\title{
Perforation of Secondary Meckel's Diverticulum due to Abdominal Trauma by a Car Accident
}

\section{Mónica Belén Martínez-Mardones ${ }^{1 *}$, Scarleth Jara Carrasco ${ }^{2}$, Dan Hartmann Schatloff ${ }^{2}$, María Teresa König Jottar ${ }^{3}$ and Anamaria Pacheco Frez ${ }^{4}$}

${ }^{1}$ Coloproctologist Surgeon, Surgery Service Hospital Urgencia Asistencia Pública, Professor at Universidad Finis Terrae, Santiago, Chile

${ }^{2}$ Medicine Intern, Universidad Finis Terrae, Santiago, Chile

${ }^{3} \mathrm{MD}$, Internal Medicine Resident, Universidad de Los Andes, Santiago, Chile

${ }^{4}$ Surgeon, Professor at Universidad Finis Terrae, Santiago, Chile

*Corresponding Author: Mónica Belén Martínez Mardones, Coloproctologist

Surgeon, Surgery Service Hospital Urgencia Asistencia Pública, Professor at

Universidad Finis Terrae, Santiago, Chile.
Received: January 29, 2021

Published: February 26, 2021

(C) All rights are reserved by Mónica Belén

Martínez-Mardones., et al.

\begin{abstract}
Introduction: Meckel's diverticulum corresponds to the most frequent congenital malformation of the digestive system. Generally, it corresponds to the accidental finding during imaging or surgical procedures. Among its complications, there are hemorrhage and perforation. The resolution is surgical and can vary between diverticulectomy versus intestinal resection.

Case Reports: Hereafter, a Meckel's diverticulum perforation case is presented, associated with abdominal blunt trauma, by a car accident in a 26 year old man.

Discussion: The relevance of this case is based on the infrequent presentation; and while the final conduct (surgical) does not change, it will help to keep in mind other differential diagnosis considering the described findings and the correct surgical resolution of it.
\end{abstract}

Keywords: Diverticulum; Meckel's Diverticulum; Malformation; Congenital; Trauma

\section{Introduction}

Meckel's diverticulum corresponds to the most frequent congenital malformation of the digestive system, with a prevalence of $2 \%$ in the population and a $1.4-4.5 \%$ reported in autopsies [1]. Its presence is attributed to the incomplete obliteration of the omphalo-mesenteric conduct during the $6^{\text {th }}$ and $10^{\text {th }}$ gestation week [2].

Generally, the natural evolution of it is asymptomatic, therefore, the diagnosis is an incidental finding during the imaging or surgi- cal procedures. Nonetheless, in a smaller percentage of patients (4 - 7\%), it debuts during clinical complications such as hemorrhage, mechanicals, infectious or mass efect [2,3] and its major incidence is shown in patients less than 2.8 years of age [2].

Clinical hemorrhage is the most common debut in the pediatrics population, meanwhile, in adults, intestinal obstruction is more frequent, usually due to intussusception and volvulus. On other hand, 
perforation is an infrequent type of presentation, being associated with foreign body in most cases [2,4-6].

Next, a Meckel's diverticulum perforation due to abdominal trauma by a car accident case is presented.

\section{Clinical Case}

26 years old man, without previous clinical history, arrives at the emergency room after a motorbike accident. His vitals signs are normal at the moment of reception, and he shows 14 points on the Glasgow coma scale. A brain CT scan without contrast is performed, where the neurological component is discarded and at physical examination does not present abdominal pain or peritoneal irritation. During the traumatological evaluation, an exposed fracture of the $4^{\text {th }}$ and $5^{\text {th }}$ metacarpal and forearm is diagnosed, this is why surgical cleaning with reduction and osteosynthesis of compromised areas is performed.

Intense abdominal pain and hematochezia appear after 24 hours post trauma surgery intervention. An Abdomen and pelvis CT scan with contrast and abdominal echography is solicited. The results show imaging compatible with perforated hollow viscus, mild hemoperitoneum and pneumoperitoneum. With these findings is decided to perform an abdominal surgical intervention.

An exploratory laparotomy is executed, displaying a Meckel's diverticulum perforation with hemoperitoneum quantified in 200 cc. Damage or perforations in other bowels are not exhibited. A resection of the perforated segment and a side-to-side anastomosis is done, without complications.

The patient evolves favorably after the intervention, displaying spontaneous diuresis, normal passing gas, and progressive oral refeeding. The aforementioned patient is discharged on the $7^{\text {th }}$ day of hospitalization.

\section{Discussion}

When Meckel's diverticulum is discussed, we face a diagnosis of exclusion, which probability of being found in incidental imaging or laparotomy, is reported in $5.9 \%$ of all cases.

Complications may vary and clinical presentation is associated with hemorrhage, inflammation, obstruction, perforation and neoplasm, all of them infrequent. The probability of appearance reach-

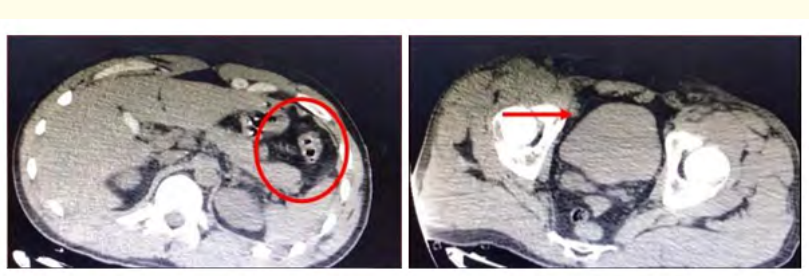

Figure 1 and 2: Abdomen and pelvis CT scan with contrast: compatibles findings with probable perforated hollow viscus, mild hemoperitoneum and pneumoperitoneum.

es its highest point at age 2 , with a $4 \%$ probability, this decreases to less than $1 \%$ at age 40 [2].

In all complication's scenarios, preoperative diagnosis is challenging due to nonspecific clinical features and multiple differential diagnoses that are faced on [10].

Focusing on perforation as a complication of Meckel's diverticulum tends to be infrequent and exceptional, in fact, there is not percentual data, since is reported in few clinical reports, generally scarce. Case reports are usually associated with foreign bodies such as chicken bones, fish bones, and batteries [4-6]. In all the aforementioned reports, preoperative diagnosis of foreign body was done through imaging, nonetheless, clinical features were nonspecific, characterized by intense abdominal pain.

A complex scenario is faced when trauma related cases are referred to. Most reports faced a patient who is registered in the emergency room after a high energy trauma, generally with normal vitals signs, who within hours presents a clinical deterioration, with associated imaging of hollow viscus perforation, the surgical resolution is mandatory. Literature provides a series of cases with a similar clinic, where Meckel's diverticulum is a side finding. None of the cases reported, a preoperative diagnosis of Meckel's diverticulum is performed, and this case was not an exception. The patient presented intense abdominal pain, associated with lower gastrointestinal bleeding. Imaging carried out suggested a compromised digestive tract, which is why the surgical intervention was executed under the impression of a more severe traumatic complication, making Meckel's diverticulum a side finding. 
The surgical resolution of Meckel's diverticulum may vary between diverticulectomy versus intestinal resection. Generally, the last one is preferred if palpable ectopic tissue in the union zone of the digestive tract with diverticulum, ischemia, or perforation are found ${ }^{3}$. In publications both resolution interventions are found, being diverticulotomy exclusive of some cases where the perforation is associated with foreign bodies.

In all 3 case reports published in the literature of Meckel's diverticulum perforation due to trauma, a surgical approach performing an intestinal resection, including Meckel's diverticulum, with anastomosis is carried out in all of them. Probably in the context of a high energy trauma in which more than $500 \mathrm{cc}$ of free abdominal fluid is described.

This situation was not the exception of the previously mentioned cases, despite the detection of lesser abdominal free fluid quantities and favorable surgical scenario. It was decided to perform only the resection of the section where diverticulum was present. The patient evolved favorably, initiating early oral refeeding and being discharged after 7 days of hospitalization.

This could be not the very first case report of Meckel's diverticulum perforation in Latin America, with no big variations in clinical findings, diagnosis and conduct of what has been published. But may be the first perforated diverticulum secondary to a high energy trauma.

\section{Conclusion}

Meckel's diverticulum is a malformation of the intestinal tract, but his complications are infrequent, being perforation the rarest of all. This time, a perforated Meckel's diverticulum associated with an abdominal blunt trauma displayed 24 hours post-accident case is presented. It will help to keep in mind other differential diagnosis considering the described findings and the correct surgical resolution of it.

\section{Acknowledgements}

We appreciate the good disposition and help of medical doctors Sebastian Soto and Francisca Aliaga.

\section{Conflict of Interest}

The authors declare no Conflicts of Interest

\section{Bibliography}

1. M Ruíz-Celorioa., et al. "El divertículo de Meckel”. Revista Medica del Hospital General de México 77.2 (2014): 88-92.

2. J Lequeta., et al. "Meckel's diverticulum in the adult". Journal of Visceral Surgery 154 (2017): 253-259.

3. Jayesh Sagar., et al. "Meckel's diverticulum: a systematic review". Journal of the Royal Society of Medicine 99 (2006): 501505.

4. Wong JHL., et al. "Fish bone perforation of Meckel's diverticulum: a rare event?" Asian Journal of Surgery 28 (2005): 295296.

5. Nikolopoulos I., et al. "Extra-corporeal laparoscopically assisted resection of a perforated Meckel's diverticulum due to a chicken bone". BMJ Case Reports (2015).

6. Ozokutan BH., et al. "Perforation of Meckel's diverticulum by a button battery: report of two cases". Ulusal Travma Ve Acil Cerrahi Dergisi 18 (2012): 358-360.

7. Choi SY., et al. "The many faces of Meckel's diverticulum and its complications". Journal of Medical Imaging and Radiation Oncology 61.2 (2016): 225-231.

8. Kazemi K., et al. "Ruptured Mekel's diverticulum following blunt abdominal trauma”. Medical Principles and Practice 17 (2008): 161-163.

9. Tummers WS., et al. "Traumatic rupture of a Meckel's diverticulum due to blunt abdominal trauma in a soccer game: A case report". International Journal of Surgery Case Reports 19 (2016): 8-10.

10. Robleh Hassan Farah., et al. "Spontaneous perforation of Meckel's diverticulum: a case report and review of literature". The Pan African Medical Journal (2015): 319.

\section{Assets from publication with us}

- Prompt Acknowledgement after receiving the article

- Thorough Double blinded peer review

- Rapid Publication

- Issue of Publication Certificate

- High visibility of your Published work

Website: www.actascientific.com/

Submit Article: www.actascientific.com/submission.php

Email us: editor@actascientific.com

Contact us: +919182824667 